\title{
WHAT, WHY, HOW OF HOMEWORK
}

\author{
Lloyd Feldmann \\ Purdue University \\ School of Technology
}

\section{$\underline{\text { Introduction }}$}

The assignment of homework is seldom mandated by our institutions or departments, but is accepted as the status quo. A familiar anecdote involves a housewife who always cut a small section from the end of a ham before cooking. When asked why, she replied "because my mother always did it!" Follow up with her mother resulted in the same response. Further follow up revealed that grandma had cut the end off because her largest pan was too small to hold the whole ham! As was noted by England and Flately [5], homework has become one of those school traditions shrouded in antiquity - "we have always done it this way!"

The purpose of this paper is to prompt you to examine your use of homework. What are the functions of homework? Why are you using that particular form? Should you change how you are currently using homework in order to achieve your goals? It is useful to stop and examine the reasons for and the appropriate use of homework in light of the desired learner outcomes. Properly utilized, homework allows the student to develop skills and to demonstrate to the instructor the level of understanding that has been achieved. It forces the students to expand on the presented material, on their own time, which expands their knowledge base. It also preserves the class time for new or additional material rather than extensive reviews. Review of the student's homework also provides information to the instructor that would allow him to modify his performance. The result would for more effective use of the instructor's and the student's available time in the achievement of the course objectives.

\section{What is homework}

Cooper [2,3], Doyle and Barber [4] and Lee and Pruitt [6] identified four common instructional goals for homework. In order of increasing complexity, the goals are 1) practice, 2) preparation, 3) extension and 4) integration.

The most common goal by far is practice or review. This is an after-the-fact assignment. It can vary from skill practice such as calculator drill to rote practice of using the trig functions on a series of similar problems to solving a series of beam problems of the same general nature. These assignments, which are meant to reinforce or reproduce what was just presented in class, frequently address surface memorization and simple regurgitation. This technique only produces a short-term effect. However, persistent practice homework that continues to emphasize the same element will have the positive effect of developing long term skill in performing these functions. The difficulty with this form of homework lies in the developing of skill rather than building a deep level of conceptual understanding. As Doyle and Barber [4] noted, "all to often these assignments are dull and unimaginative producing little more than boredom for the bright student." 
A second instructional goal of homework is preparation by the student for the material to be addressed in the next class. The purpose is for the student to read sufficiently ahead to obtain background information for the next class. One method is to assign an example problem out of the next section with a couple of values changed. Depending upon the instructor confidence level, one of the simple text problems, which normally are paraphrases of an example, can be assigned. The steps are outlined by an example, but to be able to follow the steps with new data, the students must read and study the material! Obviously this is a totally different approach but one that can be very effective in helping the students understand the material while it is presented, rather than relying totally on the practice homework. Sometimes, just knowing that a new term exists and something about its context can improve the in-class learning process rate. Most often preparation is an add-on to the practice assignment.

Extension homework would more properly be the correct type for our college level students, especially after the freshman year. Extension assignments encourage the student to examine and expand upon the in-class presentation using previously learned material. If the assignment can be personalized by the student, i.e. "find an application and describe it for the next class", the lesson is more quickly and deeply learned. These assignments are difficult to achieve on a daily or weekly. Perhaps a lab exercise can be the expanded into the background and then into another application. The research report or project is another use of this method. Unfortunately, this use is usually reserved for graduates or upper level under graduates. If this type of assignment can be assigned and successfully completed by freshmen, the learning skills achieved by these students can positively influence their success throughout their academic career.

The fourth homework instructional goal is integration. This type of assignment forces the students to combine many different skills and concepts to produce a project. The classic application of an integration project is the capstone course. It is unfortunate that we frequently feel that we have to wait until the senior year before a student is ready for good project development. One aspect that makes some capstone project so successful is the fact that the assignment is individualized or small group oriented rather than generally assigned to the whole class. Almost anyone will respond to individual attention.

A fifth goal of homework that is seldom mentioned is feedback to the instructor. I view homework and quick quizzes as the quickest methods of determining how well the students understand the presented material. This applies to development of the basic concept as well as its application to new situations. Care must be exercised when utilizing the services of a grader to that ensure that this essential information is not lost. Often, the instructor can observe subtle variations that may elude a grader but indicate an insufficient development that warrants additional class attention.

Why should you consider assignment of homework

Bloom's Taxonomy of Educational Objectives lists learning in a series of progressively greater degrees of understanding. These "degrees" are 1) knowledge of individual facts, 2) comprehension of their meaning, 3) ability to apply them, 4) analysis of a structure for application of the elements, 5) capability to design a structure, and 6) evaluation of the design and it's use. A quick glance at the levels of Blooms taxonomy shows the correspondence of 
learning objectives as we progress from the first to the fourth type of homework. While integration type homework correlates with Blooms top level, we must realize that basic skills must be developed before extended application can occur. This suggests that we should mix types of homework in order to not only develop basic skills but build conceptual understanding, application and evaluation ability. However, all of us expect our students to come to our classes with some background such as high school, experience or a prerequisite class. Therefore, those of us that are assigning homework are, to some extent, already utilizing elements of the third and fourth level goals of homework

After comparing 17 research reports since 1962, Cooper [2] determined that approximately $70 \%$ of the data showed a positive effect for those students that did homework. The indications are that the major portion of the benefit is derived from sitting down and doing the homework. The remainder of the benefit occurred when the instructor evaluated and commented on the submitted work. The conclusion is that any homework is much more effective than no homework.

\section{How should we decide what to do}

Before deciding what mix of goals to utilize in future homework assignments, there are several inter-related administration factors which should be considered. A few of them are 1) method and quality of feedback, 2) time required to accomplish (yours and theirs) the assignment, 3) type of evaluation, and 4) frequency of assignment and of evaluation.

Closely allied to the quantity of the homework assignment is the frequency of the assignments. There is wide variation, depending upon the nature of the course. Basic courses that contain a large volume of new material may be best served by daily or weekly assignments while lab or design courses may benefit by longer periodic or a single project report. However, evidence shows that restricting the assignment to a small amount of material and shorter time span improved the understanding and performance for that particular course segment. Sokol [7] radically increased the amount of homework from approximately 1 hour per credit to about 3 hours per credit, but also increased the effect of the homework on the course grade. The increase in homework accomplished directly correlated to an increase in exam scores. Burman [1] changed a course from a single comprehensive final to two case studies (a small group assignment) for $50 \%$ of the course grade plus the original comprehensive final for the remaining $50 \%$. The overall average for this class was significantly better with very few poor final exams.

Dole and Barber [4] noted the one factor upon which most researchers are united. This factor is that students should have useful feedback. While a grade is one form of feedback, additional written or verbal comments provide corrective action and motivation for the student. Homework with instructor comments is typically positively correlated to higher achievement. Ungraded homework exhibited noticeably lower achievement. While there is some question on how much feedback to include on any one returned assignment, the current philosophy is to limit comments to the most important three to five items. The items should include positive as well as negative comments to reinforce positive behavior as well as correct errors.

Researchers are also in agreement that the maximum usefulness of the feedback occurs when the comments are returned immediately, or at least very soon. Comments that are delayed beyond application to the next homework set have lost a great deal of its value. Surveys indicate 
that students often do not even read the comments on the homework if it is returned too late to be applied to the next assignment.

The amount of time to accomplish the assigned homework must be considered with respect to both the superior and the slower students. As Doyle and Barber [4] noted, "- - teachers almost invariably think an assignment will take less time than students actually spend on it". What appears easy to you may require many hours of work for your students, especially those who are having difficulty. One technique to estimate the amount of time required by the student is to multiple by three or four the time that it took the instructor, or grader, to do the homework.

It is also important to remember that students are typically enrolled in more than one course and each class has its own set of homework assignments. It is critical to allow enough time for the slower, but capable, students to complete the assignments for all of their classes. Failure to allow for this factor could lead to the overloaded student dropping your class. A secondary problem is that more class time will be devoted to catch-up and less to expanded or new material.

On the instructor side of the coin, deciding upon the appropriate homework level and exactly what to assign requires a lot of time. To process the homework also takes a finite amount of time. The labor intensive extreme of this process is to collect each assignment, the instructor to fully grade each portion of the work, assign values, annotate the errors, and suggest alternative solution methods. The highest student utility occurs with the return of the assignments to the students, with a copy of the instructor's solution method and answer, the next class period. The opposite end of the scale is to not collect the homework but ask the students if they have any questions. Those questions are then discussed in class. Most instructors use a method somewhere between these two extremes. Several of the methods used are 1) just check for completeness of the problem development, 2) check for the correct answer, 3) sample one or two problems for full evaluation and assign that grade for the homework, 4) let a grader evaluate the work based on the instructor solution and 5) have each student pass his work to another student to grade as the instructor reviews the material in class. Obviously there is a significant variation in the amount of processing time required by the instructor for each of these methods.

\section{Conclusions}

By examining the goal levels of the types of homework and the various methods of administering homework, an optimal method or combination of methods that is amenable to both the students and the instructor can be determined. As the students develop from first semester freshman, the homework should increase in complexity to include a combination of instructional goals. The quality and timeliness of the homework feedback must be maintained at as high a level as is practicable. The use of graders allows more material to be examined but reduces the feed back to the instructor. Consider the homework as both a students learning tool and a progress report of the instructor presentations. Homework can be a major tool for helping the students achieve the course objectives through accomplishing the homework assignments as well as improved instructor performance. 
Session 1275

\section{References}

1. Burman, J (1992). "Out-of-Class Assignments as a Method of Teaching and Evaluating Law Students": Journal of Legal Education, 42, 447-457

2. Cooper, H (1994). The Battle Over Homework: An Administrators Guide to Setting Sound and Effective Policies: Thousand Oaks, CA, Corwin Press Inc

3. Cooper, H (1989). Homework: Longman, NY

4. Doyle, M and Barber, B (1990). Homework as a Learning Experience. $3^{\text {rd }}$ Ed, National Education Association

5. England. D, and Flatley, J (1985). Homework - And Why. Bloomington, IN: Phi Delta Kappa Educational Foundation

6. Lee, J and Pruitt, K (1979). “Homework Assignments: Classroom Games or Teaching Tools?”: Clearing House, $53,(1), 31-35$

7. Sokol, P (1993): "Improvements in Introductory Physics Course”: New Directions for Institutional Research, 78, Summer 1993, 41-44

Biography

Lloyd Feldmann received a BSME from the University of Arizona, an MSE from Purdue University and an MA in Adult Education from Ball State University. He served ten years in the U S Navy as a Naval Flight Officer. He then worked eleven years for Cummins Engine Company in a variety of industrial engineering positions. He has also taught as a full-time lecturer in the Mechanical Engineering Technology Department at IUPUI, Columbus campus, for seven years. Currently he is an assistant professor in the MET Department of the Purdue University School of Technology at Columbus. Questions or comments can be directed to (812) 348-7214 or lfeldman@iupui.edu. 